\title{
Sustainable Urban Agriculture Land Use Practice for Thika Town
}

\section{Onguso Malitinus Maina*, Munala Gerryshom, Mugwima Bernard Njuguna}

Centre for Urban Studies, Jomo Kenyatta University of Agriculture and Technology, Nairobi, Kenya

Email address:

malti7ca@gmail.com (O. M. Maina)

${ }^{*}$ Corresponding author

\section{To cite this article:}

Onguso Malitinus Maina, Munala Gerryshom, Mugwima Bernard Njuguna. Sustainable Urban Agriculture Land Use Practice for Thika Town. International Journal of Sustainable Development Research. Vol. 5, No. 1, 2019, pp. 24-29. doi: 10.11648/j.ijsdr.20190501.14

Received: March 6, 2019; Accepted: April 16, 2019; Published: May 15, 2019

\begin{abstract}
This paper looks at the residents of Ngoingwa Estate on their attitudes towards sustainable urban agriculture land use practice within their urban set up. The pursuit of food security, alternative food systems, employment, fresh food, the unpredictable food prices, enhanced communal ties among others are the basic benefits of urban agriculture. A mixed method (purposive and non-probability) approach was adopted and both qualitative and quantitative data was collected from primary and secondary data sources by the use of questionnaires, photography, and sketches. A total of 196 questionnaires were administered analyzed by the use of SPSS and Microsoft Excel programs. The results are presented in percentages and deductions done against them. It was found out that $60 \%$ of the residents are willing, and $39.3 \%$ are actually practicing some forms of urban agriculture. It was found out that the current urban development plan for Thika and the Kiambu County Spatial Plan have not handled matters of urban agriculture, there have not been change of users to agriculture (2016-2017), land subdivision continue to eat into into former agricultural parcels, there was no data on sustainable urban agriculture land use practices within Ngoingwa, Thika Water and Sewerage Company prohibits residents from utilizing their water mains for agricultural purposes as well as the county/neighbourhood regulations and policies that prohibit urban agriculture. The study recommends that an integrated land use framework that involves building designs, appropriate building materials, exploration of vertical and rooftop farms, revision of existing plans to include urban agriculture and hiring of extension officers to guide farmers on urban agriculture.
\end{abstract}

Keywords: Food Security, Land Use, Sustainable Practices, Urban, Urban Agriculture

\section{Introduction}

The Kenyan government has been restructuring and privatizing extension services to improve delivery extension services as supported by Kamau [8]. The reality of urbanization has seen urban managers, urban dwellers, policy makers, activists among others to progressively embrace urban agriculture as a means of food sustainability. Mwangi [12] notes that urban development has put excessive pressure on agricultural land as it continues to decrease the size of former agricultural areas. The merits of urban agriculture are evident in more food secure households, appealing spatially planned neighborhoods, shorter or reduced need of transportation to the markets which contribute to cities that are more energy efficient and sustainable, creates employment locally as argued by Eriksen et al [3].
Urban agriculture also contributes to Gross Domestic Product according to the Kenya Urbanization Review [19] upon value addition at the macro level. At the household level, it leads to reduction in the cost of food, enhanced health by quality food, food security and enhanced neighborhood ties. Urban agriculture can also be a way of sharing knowledge and skills on farming. It can be an avenue for practical learning for students, parents and general public. The aesthetic value and the fact that it can act as a carbon sink, enhancing urban design and spatial planning is welcome. Taylor [15] argues that upon well articulation into the society, urban agriculture can influence policy, regulations and legislation.

Despite all this, urban agriculture has not been given the emphasis by those in authority and policy makers who have focused their efforts on infrastructure and other development 
issues. Until the current Kenya Government's "Big 4 Agenda" was pronounced, there had not been an effort to ensure food security that provides commodity funding and training for farmers as reported by Kippra [10].

Current Urban Development Plan for Thika provides for agriculture in the peri-urban and other areas whose sustainability is not documented. Records from the Physical planning department indicate that there has been more change of users from agricultural and residential to commercial, residential high-rise developments, comprehensive developments without agricultural aspects. Land subdivisions within the municipality have been done beyond the minimum $0.045 \mathrm{Ha}$ for housing developments as recorded at the Thika physical planning department [16]. Former agricultural and residential single dwelling estates like Makongeni and Ngoingwa where residents practiced agriculture are now changing their development character to accommodate highrise developments that block sufficient sunlight to the adjacent properties reducing the food production. In Ngoingwa, land dedicated for urban agriculture relies on rainfall with notable irrigation along Thika River.

The study was borrowed from Cognitive Dissonance Theory as fronted by Festinger [5]. Accordingly, people, at some point, act in a manner that is not in line with their own beliefs/attitudes/opinions and thus in a way that there is a warning if such comes to pass. Thus, getting to know of this anomaly will cause discord, and will inspire one to work on the discord. Then, change will occur in either beliefs actions or perceptions.

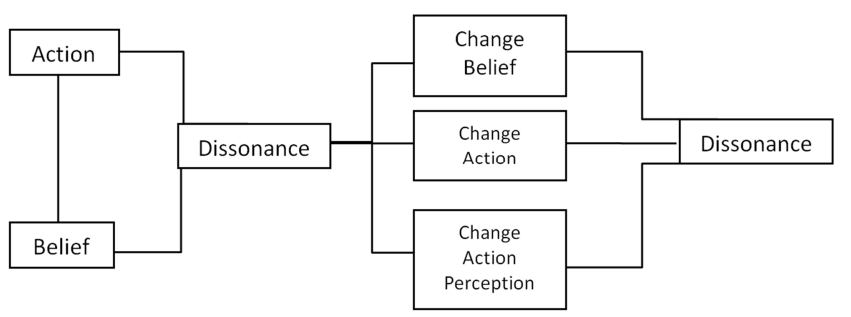

Figure 1. Theoretical Scope: Festinger [5].

In the Figure 1 above, the actions here are various efforts towards urban agriculture. In this study, we are studying how people experience tension or discomfort when their beliefs or attitudes do not match their behavior that ultimately has an influence on urban agriculture. In decision making for or against urban agriculture. This makes the decision maker experience dissonance. Any decision that will be made will imply foregoing the benefits and disadvantages of either decision.

The other theory of change is concerned with a comprehensive description as to how and why a given change is expected to happen in a given context. The theory of change first identifies the long term end results then works backwards to ensure that all conditions necessary to achieve that desired long term end are put in place as shown in figure 2 below.

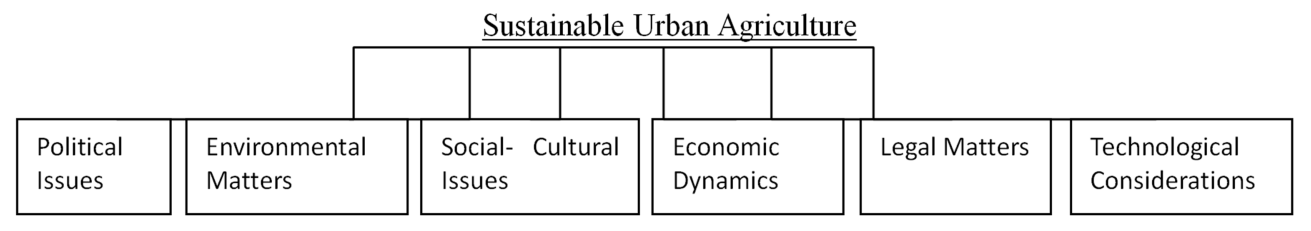

Figure 2. Theory of Change in Urban Agriculture (Source: Author, 2018).

The above connecting outcomes are then works backwards to the current situation on the ground and a completing framework is developed to drive them to the desired outcome. Then assumptions are identified, indicators and interventions are developed and identified respectively towards the desired outcome, sustainable urban agriculture.

\section{Literature Review}

The Urban Design Lab [17] defines urban agriculture as farming in the cities. Samer, [13] gives a scope of urban agriculture to include urban farming, urban gardens, domestic gardens, intra-urban agriculture, peri-urban agriculture, peri-urban farming, green roofs, window farm, irrigated urban agriculture, urban landscaping, suburban livestock farming, urban beekeeping, food security, urbanization, land-use change, agricultural systems and landuse planning.

Mougeot [11] categorizes urban agriculture into scale, type and ownership. That urban agriculture can either be micro or macro urban agriculture. Micro scale urban agriculture is in the form of walls, gardens and courtyards. Macro urban agriculture can be in the form of commercial scale farms, nurseries and green houses. Other forms are small communal gardens, individual allotments, gardens, parts of parks, green houses, green roofs, potted plant or even a large farming system. The variety of crops grown will rely on preference of the urbanites, the commercial value if for sell, prevailing climatic conditions, availability of seedlings and local authority guidelines as argued by Taylor [15].

According to UNDP [18] urban agriculture produces between 15 and 20 percent of the world's food. Food security has been a concern to leaders of sub Saharan Africa, middle and low income countries. The second goal of the United Nations Sustainable Development Goals strives to end hunger, achieve food security, improved nutrition and promote sustainable agriculture. Thus, a change in attitudes of urban residents, a change of the global food and agriculture systems is needed to feed the global hungry that continues to move to the urban areas.

In Brazil, about 120,000 middle and low income groups practice urban agriculture for subsistence. During the 
colonial times, urban agriculture was prohibited because it did not augur well with the colonial regime and aspirations as found out by Taylor [15]. The author reports that food insecurity was rural challenge until urban poverty became a challenge to urban dwellers. Urban dwellers in African cities are more dependent on the cash economy to afford the food system and a hitch in the system can cause a bit of uncertainty.

Urban agriculture is meant to boost economic the economic pillar of the Kenya Vision 2030 that points to maintenance of a sustained economic growth of $10 \%$ per annum. It identifies consolidated agricultural reform. The initiative seeks to review and harmonize the legal framework to rationalize contradictory development, regulatory, licensing, processing, and roles of agricultural institutions. Kamau [1] argues that it will modernize agricultural production, improve service delivery and harmonize the regulatory legal framework towards self sustaining food security.

It is meant to enhance food security in urban areas according to Danso \& Hamel [4]. It reduces the cost of food for the urban dwellers, enhance urban self support systems, it has psyco-social benefits of farm labour that bolsters self esteem, the aesthetic benefit of greening their city, larger farms engage in community oriented programmes such as skills enrichment, job training and other educational programmes, it can be used to inform modern approaches to urban design that initially were focused on hard spaces, open spaces and green spaces by emphasizing urban agriculture as part of green infrastructure as argued by Samer [13] and social capital as other benefits. It reduces distances between rural farms and the urban areas, it provides a platform for people to come together for mutual benefit as it provides a common identity to urban residents, it has the possibility to reduce urban heat island effects and mitigate urban storm water impacts as stated by Ackerman et al [1] and providing more fresh food. It provides an alternative food system as showed by Altieri et al [2] in the wake of reduced production in the rural areas. Further, it inspires while giving hope as well as addressing the issue of food quality from unknown sources and self supply, it provides a platform for social cohesion and development of local businesses as reported by Glavan et al [7]. Some of the crops produced are used for healing therapies as showed by Fredrich [6]. Further, Taylor [15] argues that it reduces the general environmental impact of food production systems, increases urban food selfsufficiency, reduces the amount of chemicals used in food production and reduce much industrial processing and wholesale and retail food distribution.

Buildings heights must be set to allow sufficient sunlight throughout the day for the crops to grow to maturity as depicted by Stanton et al [14]. Kirankumar et al [19] illustrates the types of building materials also determine the survival of food crops grown. Where the above two conditions are not met, then suitable plants are chosen that can do well under the prevailing conditions or other forms that are not ground level adopted. Further in their investigation, they recommend dense concrete as walling material because of its high thermal conductivity, specific heat and its density. Landscaping should also take cognizance of the type of shadow cast to provide sufficient light to the crops. A number of crops that do well in shades are recommended with the understanding of full sun, partial shade and full shade.

\section{Methodology}

The study adopted a mixed method approach as it assisted in obtaining a more complete and comprehensive account of the enquiry. Non probability sampling procedure was adopted and specifically, purposive sampling was used to collect the data. The quantitative research was in the form of close ended questions in a questionnaire that provided numerical evidence that allowed statistical analysis.

The study targeted households in Ngoingwa Estate of Thika Town that are projected by KNBS [9] to be 2,874 . With a margin of error of $7 \%, 95 \%$ confidence level and a response distribution of about $70 \%$, a sample size of 196 was arrived at using the formula below by Bereson, M. L et al [3].

$$
\begin{aligned}
\text { Required sample } & =(Z \text {-score })^{2} * \operatorname{StdDev}^{*}(1-\operatorname{StdDev}) /(\text { margin of error })^{2} \\
& =\left((1.96)^{2} \times .5(.5)\right) /(.07)^{2} \\
& =.9604 / .0049 \\
& =196
\end{aligned}
$$

Purposive sampling was adopted because the study was interested in the residents within the township who practice some form of urban agriculture. The researcher conducted a pilot study that consisted of 5 questionnaires to assist in fine tuning the questionnaire. Data collection instruments involved the use of observation, interviews, photography and observation. The data collected was coded into Microsoft Excel (2012) and SPSS (2017) for quantitative analysis. Likert scales in the questionnaires and semi-structured indepth interviews constituted the qualitative part of this research. Maps were be used to analyze spatial distribution of various phenomena, data collection analysis and inferences.

Consent was sought from the respondents before administering the questionnaires and the interview schedules assured the respondents of the confidential nature of the research. All other sources of information and data has been well acknowledged and citation given accordingly. The researcher takes full responsibility for errors committed in this paper. 


\section{Findings}

The area of study's location with adequate infrastructure and accessibility gives it an upper hand to the produce's market accessibility. The ready population provides an immediate market for the produce. The moderate climate of the area creates a conducive environment for plant growth. The foregoing points out to the potential of urban agriculture in the area of study that needs to be supported in line with the socio-economic and political landscapes for the reasons mentioned.

Urban farmers in Ngoingwa plant cereals, legumes, vegetables, tubers, animal feeds and fruits. The crops are grown within their properties, outside their properties along their boundary walls, on empty plots, along road reserves along riparian reserves and along the banks of existing swamps.

Competition for land resource for urban agriculture vis a vis other uses is one of the major challenges. Accordingly, most urban agricultural activities happen on plots designated for development or those that construction has not yet started. Insecure land tenure is a challenge to the farmers. The challenge with the poor urban soils is compounded with the inadequate extension officers to guide the willing urban farmers on the best practices given the nature of the soils.

Building designs have not considered the effects of solar radiation on urban soil moisture and their negative impacts on crop productivity. Some areas have created concrete surfaces, cabbro surfaces, tarmac surfaces or compressed murram surfaces that have significantly increased surface run off that has a great potential in damaging crops.

Unreliable rainfall patterns and general scarcity of water for irrigation has resulted to urban farmers using waste water. Urban agriculture is not in the list of water supplied by THIWASCO. Coupled with this is the lengthy process of acquiring licenses to drill borehole water for use for urban agriculture. The extraction of river water is also met with challenges from the many environmental bodies. The use of contaminated water for irrigation purposes and the use of chemicals for the intensive farming. The challenge of pests and their effects come indirectly in the high cost of pesticides, resistance to the pesticide used and the inability of farmers to identify the kind of

There is lack of extension officers within the study area. There was no known extension officer for Ngoingwa from the county government. Farmers in Ngoingwa seek for their own means of accessing extension officers for their varying needs. Lastly theft of crops by human and trespassing through urban farms by human and animals is the other challenge to urban farmers.

The respondents (46.4\%) were positive that urban farming has contributed to food availability in Ngoingwa but has not reduced the amount of money set aside for buying food in the family. It imples that some respondents could have not experienced the potential of urban agriculture. About $40 \%$ dissented to the proposal that urban farming could lead to reduced food prices. This may be attributed to the knowledge of the respondents on market dynamics of food prices. $90 \%$ of the respondents agreed to the fact that urban farmers provide fresh food to the urban dwellers. About $74 \%$ of the respondents did not think that urban farmers ensure a constant supply of food. This could be attributed to the seasonal shortages that may not be met by the urban farmers to the entire Thika population. The negative inclination to the possibility of urban farming having health benefits to the people in Ngoingwa would be because of the location of the urban farms on road sides, unused properties and food from the rural areas. $52 \%$ of the respondents felt that urban farming provided an alternative food provision system. This implies that, if urban agriculture is given more providence, then Thika can be a more food sustainable urban area.

$100 \%$ of the respondents agreed that urban agriculture leads to job creation. $64.8 \%$ of the respondents feel that urban agriculture is an alternative source of urban incomes.. But $40.0 \%$ of the respondents felt that urban farmers would require another job. This can be attributed to inadequate success stories on urban agriculture in the study area. A $47.1 \%$ felt that urban farmers do not make money like other people working within an urban area. This implies that there need to be incentives that assist urban farmers market their produce. This is because $47.2 \%$ of the respondents felt that there are many long term benefits of urban farming. $44.7 \%$ of the respondents felt that the value urban farming added to communal wellbeing is quite clear. This means that there is value that urban agriculture adds to community values of wellbeing.

When asked whether it provides a common identity to the ward residents, $46 \%$ of the respondents disagreed with only $27.3 \%$ feeling positively about it. $58.5 \%$ of the respondents felt that indeed urban farming plays a big role in fighting urban poverty, only $23.9 \%$ felt otherwise. $39.9 \%$ of the respondents slightly felt that urban farming has had an influence on planning policies and regulations within the study area.

Respondents were further asked whether urban farming has influenced planning regimes within their area. The outcome showed a shared outcome of $33.3 \%$ for those who felt so. $71.6 \%$ of the respondents felt that there has not been enough effort from the side of the county to encourage urban farming especially in provision of land area for the purpose. This also reflected to the fact that the county has not provided extension officers to support urban farmers.

On zoning guidelines, $28 \%$ of the respondents who said that the county has not set aside any land for purposes of urban agriculture. $29.6 \%$ of the respondents agreed that their approved building plans have an area that can be utilized for urban farming. While at it, $71.1 \%$ of the respondents felt that given an opportunity and resources, they can amend their approved building plans to accommodate an aspect of urban agriculture. $65.4 \%$ of respondents feel that urban agriculture contributes to fresh air in their neighborhood, while $77.5 \%$ feel that is helps in the reduction of soil erosion. $68.6 \%$ of the 
respondents felt that they did not have enough space for urban farming within their properties. This indicates their willingness to modify their building designs to accommodate urban farming given an opportunity. Interestingly, $58.6 \%$ of the respondents also felt that they could do with a bit of training to make use of the currently available space for urban farming. The other $36.5 \%$ seem to have knowledge on how to utilize the remaining empty space within their properties for urban agriculture.

The shape of individual plots did not make the respondents feel that it had an impact on urban farming. The impression the shapes of the individual plots did not make the respondents feel, in a significant manner that it hinders urban farming. However, the respondents felt, to a great, extent, that the arrangement of other uses within their properties does not support horizontal agriculture.

On reduction of urban heat waves, the percentage of those who felt it had an impact to those who felt otherwise was almost equalled. This can be because of the dotted urban farming activities within the study area, the knowledge the respondents have on the advantages of urban agriculture and the general greenery of the study area.

An integrated land use practice creates an environment that is harmonious with urban agriculture activities. Land use practices point to development control measures that do not restrict urban agriculture. Design considerations are focused on the housing typology that can support the forms of urban agriculture to maximize productivity. That means that residents need to understand what kind of crops they should opt for as the seriousness of the canopy and shadow cast has negative impact on some crops. This can be mitigated by prior design that takes into consideration of the path of the sun. Residents need a paradigm shift from the current attention to horizontal farming to vertical or rooftop farming especially in already built up areas that restrict the amount of daylight sunshine.

\section{Conclusion}

The research revealed that urban agriculture depends on the people's attitudes to development control and land use regulations, socio-economic benefits, health benefits, type of crop grown and the expected satisfaction derived from urban agriculture. Physiographic determinants like availability of water, type of soil, topography of the area among others which seemingly affect urban agriculture can well be catered for by expertise of agricultural extension officers. Planning and architectural design considerations that naturally promote urban agriculture can be factored in plans for urban areas in the long run even by manner of revisions of the current approved plans. This paper, therefore, proposes an approach that brings together aspects of the environmental considerations, social cultural practices, economic dynamics, new and smart technological approaches and legal consideration to bind urban agriculture within the urban realm.

\section{Recommendations}

Policies to ensure that urban agriculture is part of the urban form should be enacted or even legislated. Development control regulations should see to it that the minimum plot sizes are adhered to and developers restrained from building beacon to beacon to enable urban agriculture to thrive. It is recommended that $0.05 \mathrm{Ha}$ be the minimum allowed plot size in urban areas. Motor vehicles kennels, septic tanks, manholes, elevated water tanks, playing areas, among others within a plot of land should be determined as to leave space for urban agriculture. Extension officers to research on crops that grow well in various uban set ups and advice urban farmers accordingly. Current regulations and neighborhood associations' opposition to cultivation within the urban areas need be reversed as they threaten urban farmers. All existing plans should be revised to cater for aspects of urban agriculture. This is intended to give residents confidence in urban agricultural activity and also enable counties to make structural adjustments and staffing to oversee full implementation of urban agricultural activities. Concentrated highrise residential areas are proposed to enable more land to be available in the urban areas for urban agriculture.

\section{References}

[1] Ackerman, K., Conard, M., Culligan, P., Plunz, R., Sutto, M. P., \& Whittinghill, L. (2014). Sustainable food systems for future cities: The potential of urban agriculture. The economic and social review, 45 (2, Summer), 189-206.

[2] Altieri, M. A., Companioni, N., Cañizares, K., Murphy, C., Rosset, P., Bourque, M., \& Nicholls, C. I. (1999). The greening of the "barrios": Urban agriculture for food security in Cuba. Agriculture and Human Values, 16 (2), 131-140.

[3] Bereson, M. L., Levine, D. N., \& Szabat, K. (2013). Estimation and Sample Size Determination for Finite Populations. Basic Business Statistics: Global Edition. London. UK.

[4] Eriksen, N. H., \& Danso, G. (2011). 'Agronomic considerations for urban agriculture in southern cities'. International Journal of Agricultural Sustainability. [Online] https://www.tandfonline.com/doi/abs/10.3763/ijas.2009.0452

[5] Festinger, L. (1957). A Theory of Cognitive Dissonance. Evanston, IL: Row and Peterson.

[6] Fredrich, L 2013. Grazing the roof: Rooftop farmer's market comes to walker's point. OnMilwaukee, [online] http://www.onmilwaukee.com/dining/articles/rooftopmarket.ht $\mathrm{ml}$

[7] Glavan, M., Istenič, M. Č., Cvejić, R., \& Pintar, M. (2016). Urban Gardening: From Cost Avoidance to Profit MakingExample from Ljubljana, Slovenia. In Urban Agriculture. In Tech.

[8] Kamau C. N. (2013) Kenya's Agricultural Reforms Sector. USDA Foreign Agricultural Service. Global Agricultural Network. Nairobi. Kenya. 
[9] Kenya National Bureau of Statistics. (2009). Kenya Population Census. Government Printers. Nairobi. Kenya.

[10] Kenya Institute for Public Policy Research. (2010). Realising the Big 4 Agenda. Kippra. Nairobi.

[11] Mougeot, L. J. A. (2000). Urban Agriculture: Definition, Presence, Potentials and Risks, and Policy Challenges. Published thesis. International Development Research Centre (IDRC). Ottawa, Canada.

[12] Mwangi, K. W. (2015) Factors Influencing Urban Agriculture Practices in Kenya. A case of Nairobi County. UoN. Nairobi. Kenya.

[13] Samer, M. (2010). Urban Agriculture. Giza. Egypt.

[14] Stanton, K. M., Weeks, S. S., Dana, M. N., \& Mickelbart, M. V. (2010). Light exposure and shade effects on growth, flowering, and leaf morphology of Spiraea alba Du Roi and Spiraea tomentosa L. HortScience, 45 (12), 1912-1916.
[15] Taylor R. J \& Lovel T. S (2013). Urban home food gardens in the Global North: research traditions and future directions. Springer Science \& Business Media Dordrecht.

[16] Thika Physical Planning Department (2018). Development Control Section. Technical Meetings Agenda Items for February to July 2018. Kiambu. Kenya

[17] Urban Design Lab (2012). The Potential for Urban Agriculture in New York City. Growing Capacity, Food Security, \& Green Infrastructure. [online] http://urbandesignlab.columbia.edu/files/2015/04/4_urban_agr iculture_nyc.pdf

[18] UNDP, (2001). Urban Agriculture: A Neglected Resource for Food, Jobs and Sustainable Cities. UNDP, New York.

[19] World Bank (2016) Kenya Urbanisation Review. Republic of Kenya. 